\title{
The aerob and anaerob performance beta-alanine supplement and ergogenic aid using to the power output variables in cy- clists: A cohort studies random model effect
}

\author{
Yeliz Kahraman ${ }^{1}$ \\ $1 \quad$ Health Science Institute of Akdeniz University, Turkey. \\ * Correspondence: yelizkahramana@hotmail.com; +90-542-822-71-62.
}

\begin{abstract}
Supplement the use of ergogenic aids in cyclist's directly have been improved the body metabolism and hemodynamic factors that are micro supplement in chancing reactions on the body muscle mass and limb muscle. Mostly knowing that, muscle power development progressive fast glycolytic and short time oxidative systems reactions. Sport competition intervals, therefore, during periods has been used specific drinks supported to cyclists. But, be obtained during should be long race times. Athletes directly needed some drug and fluid intake to prevented from metabolic breakdown rapidly the dynamic physiologic performance factors. Beta-alanine supplementation can be direct muscle performance development affects the anaerobic metabolism and capacity. It should be determined how the cyclists will use the competitive and training period intervals can increase the cyclists specific sprint and endurance race performance. Science cyclist International Road doses will be created in which, intervals can random effectively the investigate. This study random a cohort studies is examined the effects of beta-alanine supplementation on aerobic and anaerobic power output in specific cyclists. Therefore, we have been databases PubMed, Scopus and Medline initial search 10 August 2020 were created prospective effect the quality of bias work concluded effect size (ES) $95 \%$ confidence interval (CI) were used in participant. Participations ( $\mathrm{N}=66$ ) have age range 25 to 38 of the using beta-alanine in training periods to endurance muscle performance, aerobic power, anaerobic power, and sprint time trials. As a result of beta-alanine improved anaerobic and aerobic power output on 4-week time-dependent trial performance condition. Significant values are obtained level factor alpha $<0.05$ and p-value analysis pre-post interactive standardization.
\end{abstract}

Keywords: Beta-alanine, supplementation, nutrition, aerob and anaerob performance.

\section{Introduction}

Application in micro-nutrition a current approach in sports science and competitive-training periodization additional international road cyclists has been obtained micro ingestion form of diet are use increase daily their consumption [1]. Additional macronutrition requirement in standard nutritional content needed are calories taken daily should be substances same time pre-training and competition and post-training and competition of the cyclists help to performance factors and muscle recovery [2]. The cyclists use ergogenic aids to conjunction their performance power output, hgmm, stroke volume therefore, generally not complete diet $[3,4]$. Increased energy formation of the muscle performance period according to like vitamin and mineral occurs ergogenic aid from same excessive obtaine long period training or competitive that macronutrition ingestion requirement [5]. Recruiment by Canada Academy of Sports and American School of Sports Medicine as suggested is three ergogenic aids class recommendation which, including a have many benefits such as completing reduce metabolism or supercompositing exercise in beta-alanine has been the groups of cyclists [6].

It is possible to see the different time combined to preserve optimal maintain performance when considering cyclists, it is important during long race times occur nutrition intake. Accordingly, groups of cyclists it is diets that will conjunction performance while consuming ergogenic supplement turned have efficiency in superior development of endurance and strength component [7,8] Cycling sports is continued the hard fight with endurance and muscle strength performance and recovery expected to take place in short periods. Condition competitions are observed in different stages and time trials over exceedingly long periods so basically is the sport of endurance [9]. But sprint performance for nature have explosive in short periods [10]. Athletes sometimes some had difficulty feeding depending on time are very hungry therefore, diet control and nutrition programs should be planned closely carefully in appropriate training processes as team and coach [11]. Dynamic performance over long periods peak values occur 
during the rapid recovery and stroke volume when power different metabolism is achieved in blood lactate optimal intervals [12].<smiles>NCCC(=O)NC(Cc1c[nH]cn1)C(=O)O</smiles>

Carnosine

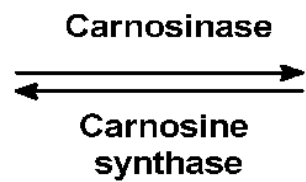

(ATP)<smiles>NCCC(=O)O</smiles>

$\beta$-alanine<smiles>N[C@@H](Cc1c[nH]cn1)C(=O)O</smiles>

L-histidine

\section{Figure 1. Complex carnosine-L-histidine metabolism of rapid insulin and glycolytic energy formation in muscle perfomance development optimal endurance sequences.}

Previous exercise and performance studies for use of beta-alanine into carnosine conjunction is aim in specific type II fibers reported that an amino acid this inductively of hydrogen ions without being induced calcium release simultaneous performed ATP-resentez in the anaerobic glycolysis cycle [13]. But this condition metabolic cycle fast recovery energy in cytoplasm can help to muscle buffering observed intramuscular adaptation $\mathrm{pH}$ buffering as regeneration activity on muscle development performance [10,14]. Investigation reported on the horses initial beta-alanine amino acid form for the metabolic carnosine type I oxidative $20 \%$ and type IIb fast glycolytic fibers $46 \%$ has become evident not type IIa fast glycolytic oxidative [15].

Therefore, developing cycling increase energy formation drug studies firstly have been a multiple antioxidant [16]. Stunning results, using to beta-alanine supplementation highly ingestion in the decade $>4$ weeks 3-6 g/day ingestion resulted in intramuscular carnosine levels within type I and type II fibers 30-80\% same performance results all during competitive and training doses [17]. Addition, intramuscular recover phase and anaerobic capacity development levels of the muscle mass between male and female 3.5-1.0 ratio in hormonal development residual sex are observed to sytokinease [16]. Same previous studies how exercise performance outputs development of endurance cyclists has not gained obvious as long time- dependent performance [18]. The reason this, in endurance performance is by tolerating rapid glycolytic energy capacities involved in the oxygen cycle over 1-3 min for performance the use of beta-alanine in the few minutes should be used as an auxiliary production [19]. Although, cyclist's group has been reported to contractile mechanics oxidation of percentage reported to cause lactate in anaerobic and aerobic capacity [20]. Increased lactate production has enabled muscle adaptation otherwise total work output capacity increase in bicycle capacity was found to correlate with the carnosine content in muscle within beta-alanine by $50 \%$ type I and type II [10]. The muscular efficient of knee and ankle limbs extensor for anaerobic capacity and aerob power output variables is important muscle development in cyclist period and pedalling mechanic [18].

The aim of this studies was to conclude the use of beta-alanine dose in the physiologic effect depend on time-related trials of anaerob and aerob power output performance in cyclists. Dose use in different time periods will be concluded at performance factor (e.g., as performance output glycolytic insulin resistive factor and aerobic residual oxygen capacity).

\section{Materials and Methods}

This study was followed methodologic quality and bias of include by independent effect size and confidence interval investigate the applied training science Pubmed, Google Scholar and Medline were data publication no limitation. All of times one year the retrospective from August 2021 (2009-2020). The Cochrane Collaboration quality controversies resolved on blind evaluated of the study authors, method, and characteristics sample size, using of the beta-alanine supplement and performance levels of cyclists. Same dose using was formed [21]. All screen evaluation generally eligibility criteria completed the study characteristics; a: participation property characteristics, b: health hydration status, core temperature used to during supplement, c: macro-nutrition standardizes before and after training and 
competitive period of their performance anaerobic and aerobic power output recorded. All statistic paired-T test comparison to between cyclist pre and post values, method Binary $\mathrm{R}$ statistics measurement therefore, mean and standart deviation operation systems windows and excel statistically significant was set the effect size and are obtained to use the measurement confidence interval low and high showed Cohen' $\mathrm{d}$ effect size 0.20 small, 0.50 medium, 0.80 high this study (SPSS 21, IBM, New York, USA; Salkind, 2010). ( $<<0.05)$.

Table 1. Criteria research eligibility

\begin{tabular}{|c|c|c|}
\hline Variable criteria & Included & Excluded \\
\hline Participation & 25 to 38 age and medical health acceptable & $\begin{array}{l}38 \text { adult and cyclist age no cy- } \\
\text { clists e.g., road, mountain, rec- } \\
\text { reational }\end{array}$ \\
\hline Method approach & $\begin{array}{l}\text { Beta-alanine blind manner and macro-micro } \\
\text { specific nutrition intake standardiza- } \\
\text { tion }\end{array}$ & $\begin{array}{l}\text { Intake caffein, alco- } \\
\text { hol before periodiza- } \\
\text { tion and training times and } \\
\text { no } \\
\text { nutrition program cyclist. }\end{array}$ \\
\hline Studies design & $\begin{array}{l}\text { Randomize and cohort single- and double-blind } \\
\text { studies }\end{array}$ & $\begin{array}{l}\text { No randomize experimental } \\
\text { condition nutrition intake }\end{array}$ \\
\hline Results & $\begin{array}{l}\text { Aerobic and anaerobic power output at least perfor- } \\
\text { mance parameter }\end{array}$ & $\begin{array}{l}\text { Aerob and anaerob power } \\
\text { output no results and con- } \\
\text { clusion eligibility }\end{array}$ \\
\hline
\end{tabular}

\section{Results}

Participations results obtained PubMed (N=26), Scopus ( $=74)$ and Google Scholar $(\mathrm{N}=56)$ total 156 research. Research data variables each statistically significant end of mean and standard error and deviation resulted random effect size estimated in effectively weighted mean difference and 95\% confidence interval. Therefore, individual results population sample size as minus standardized [22]. Sub-results analysis into training protocols, strength and endurance, sprint and combined power output was prevented from of the bias in study specific development should be sport science and international cyclists performance could determine and evaluate. 

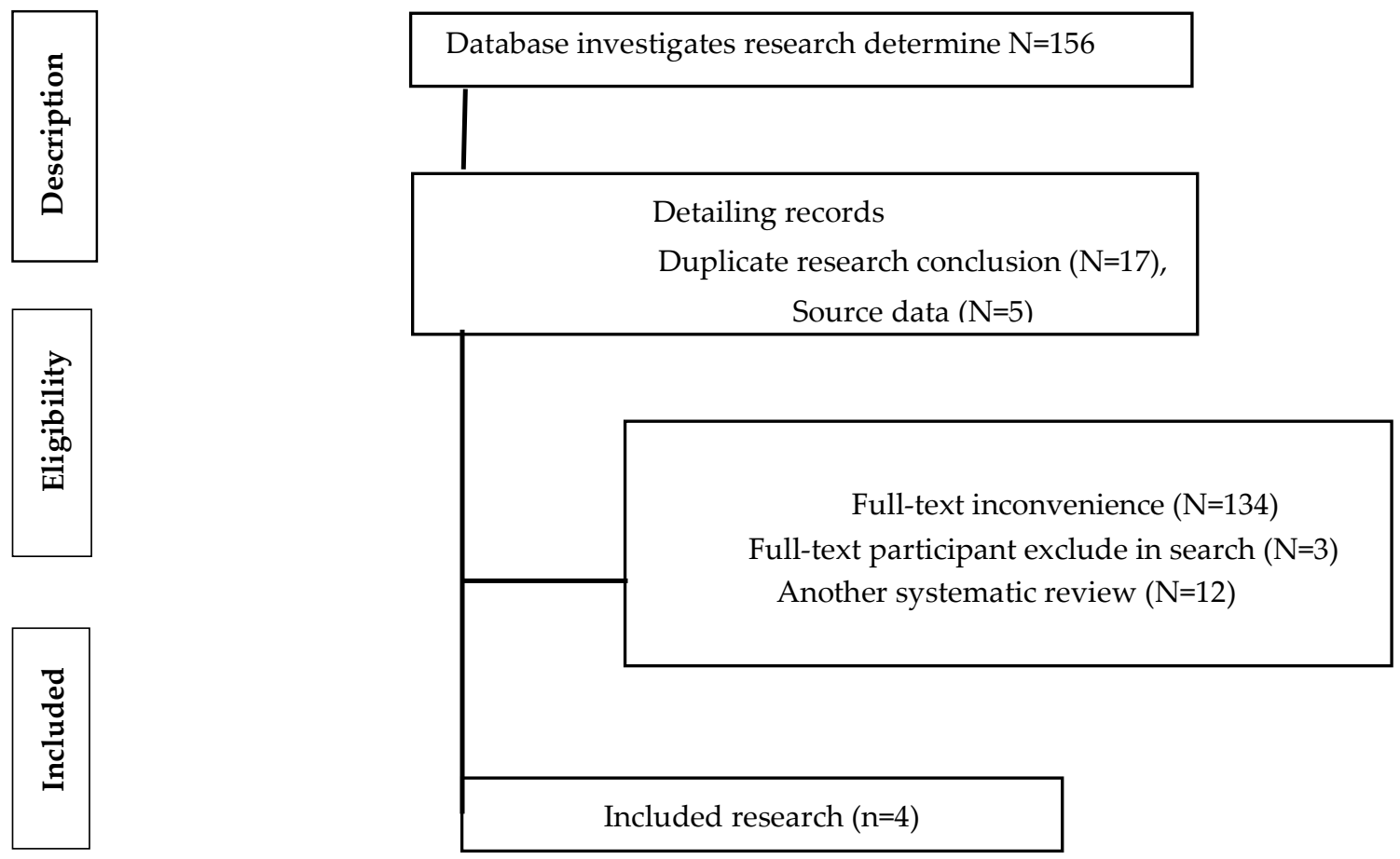

Figure 2. Flow diagram PICO quality checklist

Participation risk of bias in blind author evaluated references listed [22]. This study propered range randomize allocation concealment; blind participation, blinding of outcome evaluate, incomplete outcome data, selective outcome reporting, other sources of bias, overall risk of bias; 2 low, 3 medium, 4 high-risk bias was evaluated as quality cochrane (Table 2).

Table 2. Study risk of bias quality obtained results

\begin{tabular}{|c|c|c|c|c|c|c|c|}
\hline Research & $\begin{array}{l}\text { Random- } \\
\text { ize range }\end{array}$ & $\begin{array}{l}\text { Allocation } \\
\text { conceal- } \\
\text { ment }\end{array}$ & $\begin{array}{l}\text { Blind par- } \\
\text { ticipation }\end{array}$ & $\begin{array}{l}\text { Incomplete } \\
\text { outcome } \\
\text { data }\end{array}$ & $\begin{array}{l}\text { Selec- } \\
\text { tive } \\
\text { out- } \\
\text { come } \\
\text { reporting }\end{array}$ & $\begin{array}{l}\text { Other } \\
\text { sources } \\
\text { of } \\
\text { bias }\end{array}$ & $\begin{array}{l}\text { Over- } \\
\text { all } \\
\text { risk of } \\
\text { bias }\end{array}$ \\
\hline $\begin{array}{l}\text { Bellinger and } \\
\text { Minahan }\end{array}$ & $\mathrm{L}$ & $\mathrm{L}$ & $\mathrm{L}$ & $\mathrm{L}$ & $\mathrm{L}$ & $\mathrm{L}$ & $\mathrm{L}$ \\
\hline James & $\mathrm{L}$ & $\mathrm{L}$ & $\mathrm{L}$ & $\mathrm{L}$ & $\mathrm{M}$ & $\mathrm{L}$ & $\mathrm{L}$ \\
\hline Howe & $\mathrm{L}$ & $\mathrm{L}$ & $\mathrm{L}$ & $\mathrm{L}$ & $\mathrm{L}$ & $\mathrm{L}$ & $\mathrm{L}$ \\
\hline Van & $\mathrm{H}$ & $\mathrm{L}$ & $\mathrm{L}$ & $\mathrm{L}$ & $\mathrm{L}$ & $\mathrm{L}$ & $\mathrm{H}$ \\
\hline Abbreviation & L: Low & M: Medium & H: High & & & & \\
\hline
\end{tabular}

Note: Evaluated cyclists reported that, results have been shown one study high risk of bias, other studies low risk of bias, same one study medium risk of bias shown this beta-alanine supplement using muscle endurance and anaerobic capacity evaluation of the power output development. 
BA supplement most anaerobic glycolytic systems when performance factors can be effect from glycolytic systems energy output and muscle performance energy. Therefore, anaerobic, and aerobic protocols by different time periods resulted in endurance and recovery of the power performance mechanics and pedalling development [23,24]. However, their acute effect was aimed. Same participation groups regardless of experience characteristics aerobic power has been limited long time periods. Anaerobic power reported that, time as periods to measurement protocols are values parameter obtainement eligibility power output reference $[25,26]$. Therefore, races cycling time-period anaerobic less were founded [5]. Reported that the most should focus on power performance changes or not. Systematic values of obtain graph presentation for not significant included in study. Peak training period and peak power development out exercise trial and test condition generally use of BA supplement has been concluded.

Table 3. BA supplement participation property aerob endurance and anaerobic capacity effect in training trial testing condition

\begin{tabular}{|c|c|c|c|c|c|c|}
\hline Parameter & $\begin{array}{l}\text { Sample } \\
\text { size }\end{array}$ & Age & $\begin{array}{l}\text { Varia- } \\
\text { ble }\end{array}$ & $\begin{array}{l}\text { Gen- } \\
\text { der }\end{array}$ & Design & $\begin{array}{c}\text { Re- } \\
\text { search } \\
\text { Code }\end{array}$ \\
\hline $\mathrm{W}$ and $\mathrm{L}$ & $\begin{array}{l}\mathrm{P}=7 \\
\mathrm{~B}=7\end{array}$ & $25.4 \mathrm{y}$ & $4.50 \mathrm{~L} / \mathrm{VO} 2$ & M & $\begin{array}{c}28 \mathrm{~d} ; 6.4 \mathrm{~g} \\
\text { Parallel }\end{array}$ & $\begin{array}{l}\text { Bellinger and Minahan, } \\
\text { 2016a }\end{array}$ \\
\hline Le & $B=10$ & $24.5 \mathrm{y}$ & $4.47 \mathrm{~L}$ & M & $\begin{array}{c}28 \mathrm{~d} ; 6.4 \mathrm{~g} \\
\text { Parallel } \\
\end{array}$ & Bellinger, 2016b \\
\hline Le & $\begin{array}{l}P=7 \\
B=7\end{array}$ & $24.8 \mathrm{y}$ & $65.4 \mathrm{~mL}$ & M & $\begin{array}{c}\text { 4-w; } 6.4 \text { g } \\
\text { Parallel }\end{array}$ & Bellinger, 2016c \\
\hline $\mathrm{J}$ & $\begin{array}{l}\mathrm{P}=11 \\
\mathrm{~B}=11\end{array}$ & $54 \mathrm{y}$ & $\begin{array}{l}3.459 \mathrm{~J} \\
3.451 \mathrm{~J} \\
\end{array}$ & $\mathrm{~F}$ & $\begin{array}{c}28 \mathrm{~d} ; 800 \\
\text { mg Par- } \\
\text { allel }\end{array}$ & Gleen et al., 2016 \\
\hline W and Le & $\mathrm{B}=12$ & $26.6 \mathrm{y}$ & $610 \mathrm{~W}$ & $\mathrm{~F}$ & $\begin{array}{l}1 \mathrm{~d} ; 1.6 \mathrm{~g} \\
\text { Parallel }\end{array}$ & Glenn et al., 2015a \\
\hline $\mathrm{J}$ & $\begin{array}{l}\mathrm{P}=11 \\
\mathrm{~B}=11\end{array}$ & $53.3 \mathrm{y}$ & $39 \mathrm{~mL}$ & $\mathrm{~F}$ & $\begin{array}{c}28 \mathrm{~d} ; 800 \\
\text { mg Par- } \\
\text { allel }\end{array}$ & Gleen et al., 2015b \\
\hline W & $\begin{array}{l}\mathrm{P}=13 \\
\mathrm{~B}=14\end{array}$ & $\begin{array}{l}31.6 y \\
30.3 y\end{array}$ & $\begin{array}{l}61 \mathrm{~mL} \\
60.4 \mathrm{~mL}\end{array}$ & M & $\begin{array}{l}\text { 6-w; } 800 \mathrm{mg} \\
\text { Cohort }\end{array}$ & Chung et al., 2014 \\
\hline W & $\mathrm{P}=10 \mathrm{~B}=9$ & $\begin{array}{l}33 y \\
32 y\end{array}$ & $\begin{array}{l}50.773 \mathrm{~J} \\
52.538 \mathrm{~J}\end{array}$ & M & $\begin{array}{l}\text { 4-w; } 800 \mathrm{mg} \\
\text { Parallel }\end{array}$ & De Salles et al., 2014 \\
\hline W & $\begin{array}{l}\mathrm{P}=9 \\
\mathrm{~B}=10\end{array}$ & $\begin{array}{l}32.6 \mathrm{y} \\
37.8 \mathrm{y}\end{array}$ & $\begin{array}{l}1993 \mathrm{~W} \\
1975 \mathrm{~W}\end{array}$ & M & $\begin{array}{c}\text { 4-w; } 800 \mathrm{mg} \\
\text { Parallel }\end{array}$ & James et al., 2014 \\
\hline $\mathrm{J}$ and $\mathrm{W}$ & $\begin{array}{l}\mathrm{P}=8 \\
\mathrm{~B}=8\end{array}$ & $\begin{array}{l}22.5 y \\
26.8 y\end{array}$ & $\begin{array}{l}67.3 \mathrm{~mL} \\
67.5 \mathrm{~mL}\end{array}$ & M & $\begin{array}{c}\text { 4-w; } \\
127.4 \text { g } \\
\text { Parallel }\end{array}$ & Howe et al., 2013 \\
\hline $\mathrm{W}$ and Le & $\mathrm{P}=8 \mathrm{~B}=9$ & $24.9 \mathrm{y}$ & $\begin{array}{c}60.3 \\
\mathrm{~mL} / \mathrm{kg}\end{array}$ & M & $\begin{array}{c}8-\mathrm{w} ; 500 \\
\mathrm{~g} \\
\text { paralell }\end{array}$ & Van et al., 2009 \\
\hline
\end{tabular}

J: Joul; W: Watt; N: Newton; Le: Lactate elimination, P: Placebo, B: Beta-alanine, M: Male, F: Female, P: Parallel, C: Cohort. 
NOTE: Lactate elimination and power output concluded in cyclists.

Bellinger and Minahan (2016a) in cyclists for sprint performance depending on race starting $41 \mathrm{~km}$ repetations to interval training session and $4 \mathrm{~km}$ and $10 \mathrm{~km}$ performed three times in supramaximal exercise section [5]. Normalize power founded that, research to $\mathrm{km} \mathrm{144.84/Watt} \mathrm{conjunction} \mathrm{with} 1.90 \mathrm{mmol}$ lactate accumulation. The resulted values showed that, 3-4. $\mathrm{km}$ has obtained 424/Watt to increased anaerobic improvement concluded (ES=0.29 moderate, $\mathrm{WMD}=23 / \mathrm{Watt} ; \mathrm{p}=0.05$ ) as statistical high effective shown. Lactate mmol levels same mean $16.1 \mathrm{mmol}$ totally significant has shown highly effective lactate power energy increase. Power increase daily progressive contraction of muscle mass as $6.4 \mathrm{~g}$ are beta-alanine groups cyclists lactate elimination resulted. Howe et al (2013) supramaximal effort $90 \%$ reach contraction concentric after HIT-30 s at 4-min mean reported that, results showed total working aerobic power optimal stroke volume/saturation and lactate elimination increase, proved recorded blood resistance, muscle heat and core temperature optimal endurance development of muscle contraction sizes effected performance development $(E S=0.27$ moderate; $\mathrm{WMD}=11 / \mathrm{Watt} ; \mathrm{p}=0.01$ ) of the showing muscle strain increase resulted to the vastus lateralis and medialis and rectus femoris and gastrocnemious sec has been shown statistical significant with $30 \mathrm{~s}$ isokinetic test conclusion time-depend specific protocol increased aimed lactate [10]. However, power output after 4-weeks beta-alanine using was increased. Other studies for peak performance development $90 \%$ MSLL 110-min after 10-min time trial functional threshold power sessions and 50\% MSSL 30-s sprint time performance determined BA groups cyclists at 10-min time trial and sequence should be aerobic power differ was effect decrease has been showed (ES=0.50 moderate; WMD: 52/Watt; ES=0.54 moderate; WMD: 21/Watt; $p=0.03$ ). Therefore, consequently, lactate evaluated finish the power output, overall effect size was taken for level alpha $\mathrm{p}>0.05$. Additional within research different testing condition peak power values size has been shown alpha level $p<0.05$.

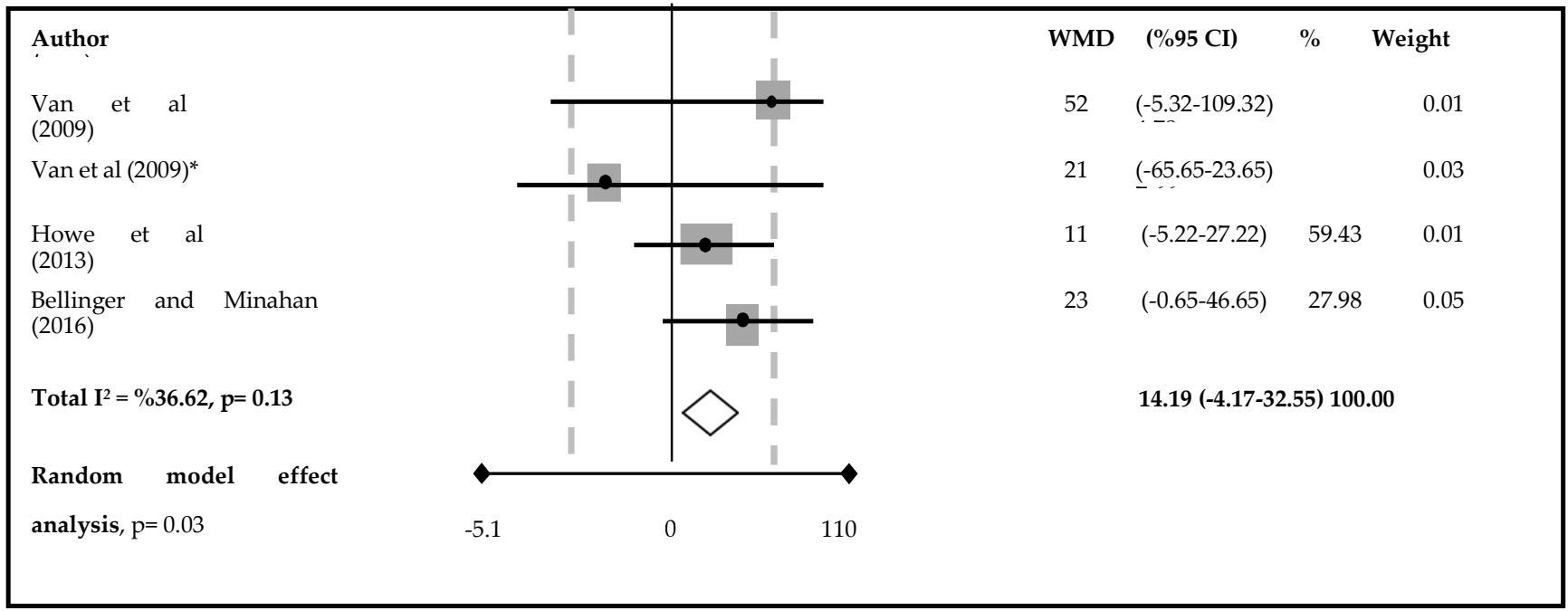

Table 4. Forest plot of BA supplement using aerobic power and anaerobic capacity of normalize power developing on power output results shown that, random effect analysis determination

Mean data concluded random anaerobic capacity peak power development showed 4 research highly effective significant and confidence intervals increase. One research experimental other three research both experimental and clinic should be [10]. Conclusion, carnosine similarly insulin levels is normal course. Single research for washout period 5 to 6 week before BA use 15-week normally stressed that, it should be in this time over 47 age is low carnosine level with relationship health insulin hormone decreased energy formation [10]. Performance of BA supplements long time race not studied in cyclist only has found sprint into muscular endurance peak systematic hormonal and insulin take from normalize power. Generally known that hours, weeks, and mount training effectively muscle hypertrophy aimed to sprint developing on muscle size effectively [5]. Therefore, sprint performance always buffering of muscle capacity be explosive in short time trial training periodization so-called micro cycle. Total capacity studies showing that, WMD: 14.19/Watt relationships between oxygen cycle, contraction mitochondria enzyme same effective 
$\mathrm{pH}$ changes with hgmm and heartbeat. However, studies are heterogeneous $\mathrm{Q}$ value is 4.73 and different have shown investigated alpha value work every significant random effect. Therefore, we showed to obtained heterogeneous $I^{2}=$ 25-50\% small [22] Van et al (2009) were obtained (CI: -5.32 - 109.32) changes pre-post differed about 4 repetitions same $1 \mathrm{~km}$ references concluded in beta-alanine will show that, highest power increases $(\mathrm{p}<0.10)$. Bellinger and Minahan (2016a) that founded (CI: $-0.65-46.55)$ was as other same trial methods. Minimum effect has been found anaerobicaerobic complex periodization application in total should 4-week beta-alanine with 800 mg short muscle energy capacity and recovery $[5,10]$.

\section{Discussion}

Over long time periods, it is believed that it can increase the effect of international road cyclist training of anaerobic and aerobic high effect time 1-day micro cycle anaerobic threshold but long-term efficiency as 4-to-8-week same periodization because estimated to power and lactate mmol increase [5, 20, 24, 25, 26, 27, 28, 29]. Male cyclist at least per week 7 hours training about $20 \mathrm{~km}$ trial load is occur 7/Watt power increase sequence of intervals but increasing mechanism in the muscle would not proper training into beta-alanine use because 48 hours or 24 hours eliminated lactate as well as recovery most speed. Beta-alanine individual dose prevent from lactate decreased must be macro carbonhidrate if use decreased, short concentric activation did not formation. Limitation must be their insulin pooled mmol ATP glycogen. Chung et al (2014) other studies as 1-hour working of muscle using beta-alanine time interval total 101 $\mathrm{km}$ road with gastronomes and soleus when carnosine with macronutrition level investigated the mean development obtained 20/Watt, similarly total load means caused $1.987 \mathrm{~J}$ power [29]. However, BA group were not randomized because there was only indicating training effectiveness [26]. High total work in this study 6-week BA using for intramuscular hypertrophy level can show regardless of muscular economy at rate of buffering fast glycolytic sprint performance peak power increase for trials 4x30 wingate performance. Aerobic capacity regardless initial load 120\% of VO2max in voluntary exhaustion of female cyclist $24 \%$ increase with training effectiveness low about lactate 5.76 mmol high intensity trial resulting of was obtained aerobic capacity $34 \%$ distal end volume increase anaerobic is noteworthy. Using of BA one day 1 gr non- contribution to performance improvement of muscle size contraction phases [27,28]. This stage short term and mean 55/Watt no significant that, evidence fatigue in post measurement accompanied to lactate accumulation $14.6 \mathrm{mmol}$ as other reported high. Other BA supplements anaerobic isokinetic above 1 min time dependent contractile mechanism the type II fibers occured $41 \mathrm{~J}$ total working no considered imported difference protocol time dependent $4000 \mathrm{~m}$ aerob performance but anaerob power high observed while increased 12.6 fatigue mmol lactate hgmm of stroke volume characteristic, limitation of working mean and standart deviation values was not specified [30]

After all, critical power has not been formed with BA-alanine using and carbonhidrate consumption short term 24 week can support as well as physiologic using no assumption ergogenic aid the short period competition and training times. In long term aerobic working modes for endurance cyclists should be macronutrition intake side effect paresthesia should not be overlooked [31]. Additional, total sprint supramaximal intensity compromise high capacity normalize power effort of short-work attribute mean age 24 and 28-day-6.4 g/day intake with recovery and injury risk of sportmenships [5]. For muscular efficient increase depending on the sprint performance protocols above ventilatory threshold should be BA supplements need to long-term showing effective training periods and 25 year and 8 -week/800 $\mathrm{mg}[10]$.

Therefore, fast contraction period 180-degree repetition 30 mechanics muscular efficient use of BA supplements in cyclists increased in performance their concluded age 27 and 4-week/127.4 g [18] Conclusion, short-term muscular efficient performance power output shown is effect supplements in cyclist but periodization for long term strategies more effect is needed professional and international road cyclist.

\section{Conclusions}

In race and competition cyclist anaerob and aerob power the BA supplements exercise finalized protocol supplements doses. Peak races sprint exercise and training for reason should be true using limitation, therefore, long term periods BA supplements few research have been obtained. Peak BA included in muscle buffering strategies within 90min [32]. Power factors when anaerob and aerob working capacity in future research for power output should lead to 
the linear effect and training period planning that may result in power out, lactate or hemodynamic parameter. Side effect factors another supplement combine or carbonhidrate status individual cyclists or team road cyclist's implementation are needed for develop. Limitation dose setting should be created according to athletes. Muscle mass and fatigue be limited in multiple energy sections.

Author Contributions: For research articles with one author all process has contributed to substantial work.

Acknowledgments: There were no authors conflicts of interest to declare. The contributions of authors included in the systemic section to carried out the examination of studies obtained findings analysis and draft table and graphs. Authors approved final this study. Authors also wish to thank their assistant professional cyclists in the design of this study.

\section{Appendix A}

The appendix is an optional section described source of a series of supplementary authors, appendixes compose of beta-alanine, sodium bicarbonate, nitric oxide, beta-hydroxy-beta-methylbutyrate.

Abbreviations: BA: Beta-alanine, CI: Confidence Interval, WMD: Weighted mean difference, HIT: High-IntervalTraining, HCO3: Bicarbonate, MSLL: Maximal steady-state lactate, J: Joul, Le: Lactate elimination.

\section{References}

1. Stecker, R. A., Harty, P. S., Jagim, A. R., Candow, D. G., \& Kerksick, C. M. Timing of ergogenic aids and micronutrients on muscle and exercise performance. Journal of The International Society of Sports Nutrition, 2019;16;2-8. https:/doi.org/10.1186/s12970-019-0304-9.

2. American Dietetic Association, Dietitians of Canada, American College of Sports Medicine, Rodriguez, N. R., Di Marco, N. M., \& Langley, S. American College of Sports Medicine position stand. Nutrition and athletic performance, Medicine and Science in Sports and Exercise, 2009;41:709-731. https:/doi. org/10.1249/MSS.0b013e31890eb86.

3. Black, M. I., Jones, A. M., Morgan, P. T., Bailey, S. J., Fulford, J., Vanhatalo, A. The effects of $\beta$-alanine supplementation on muscle pH and the power-duration relationship during high-intensity exercise. Front Physiology, 2018;9;1-13. https:/doi.org/10.3389/fphys.2018.0011.

4. Hobson, R. M., Saunders, B., Ball, G., Harris, R. C., \& Sale, C. Effects of $\beta$-alanine supplementation on exercise performance: A meta-analysis. Amino Acids, 2012;43:25-37. https:/doi.org/10.1007/s00726-011-1200-z.

5. Bellinger, P. M. $\beta$-Alanine supplementation for athletic performance: an update. Journal of Strength Conditioning and Research, 2014;28:17511770. https:/doi.org/10.1519/JSC.0000000000000327.

6. Robinson, E. H., Stout, J. R., Miramonti, A. A., Fukuda, D. H., Wang, R., Townsend, J. R., \& Hoffman, J. R. High-intensity interval training and $\beta$-hydroxy- $\beta$ - methylbutyric free acid improves aerobic power and metabolic thresholds. Journal of International Society and Sports Nutrition. 2014; 26: 1-11. https:/doi.org/10.1186/1550-2783-11-16.

7. Oliveira, C. C., Ferreira, D., Caetano, C., Granja, D., Pinto, R., \& Sousa M. Nutrition and Supplementation in Soccer. Sports, 2017;5.28-35. https:/doi.org/10.3390/sports5020028.

8. Felippe, L. C., Ferreira, G. A., Learsi, S. K., Boari, D., Bertuzzi, R., Lima-Silva, A. E. Caffeine increases both total work performed above critical power and peripheral fatigue during a 4-km cycling time trial. Journal of Applied Physiology, 2018;124:1491-1501.https:/doi.org/10.1139/apnm2019-0992.

9. Erp, T., Sanders, D. Demands of professional cycling races: Influence of race category and result. European Journal of Sport Science, 2020;16:112. https:/doi.org/10.1080/17461391.2020.1788651.

10. Van Thienen, R., Van Proeyen, K., Vanden Eynde, B., Puype, J., Lefere, T., \& Hespel, P. Beta-alanine improves sprint performance in endurance cycling. Medicine and Science in Sports and Exercise, 2009;41:898-903. https:/10.1249/MSS.0b013e31818db708.

11. Chung, W., Baguet, A., Bex, T., Bishop, D. J., \& Derave, W. Doubling of muscle carnosine concentration does not improve laboratory 1-hr cycling time-trial performance. International Journal of Sport Nutrition and Exercise Metabolism, 2014;24:315-324. https:/doi.org/10.1123/ijsnem.20130125.

12. Burke, L. M., Castell, L. M., Casa, D. J., Close, G. L., Costa, R., Desbrow, B., Halson, S. L., Lis, D. M., Melin, A. K., Peeling, P., Saunders, P. U., Slater, G. J., Sygo, J., Witard, O. C., Bermon, S., \& Stellingwerff, T. International Association of Athletics Federations Consensus Statement 2019: Nutrition for Athletics. International Journal of Sport Nutrition and Exercise Metabolism, 2019;29(2), 73-84. https://doi.org/10.1123/ijsnem.2019-0065.

13. Dutka, T. L., Lamboley, C. R., McKenna, M. J., Murphy, R. M., Lamb, G. D. Effects of carnosine on contractile apparatus Ca2? sensitivity and sarcoplasmic reticulum Ca2? release in human skeletal muscle fibers. Journal of Applied Physiology, 2012;112:728-736. https:/doi.org/japplphysiol.01331.2011.

14. Mannion, A. F., Jakeman, P. M., Dunnett, M., Harris, R. C., \& Willan, P. L. Carnosine and anserine concentrations in the quadriceps femoris muscle of healthy humans. European Journal of Applied Physiology and Occupational Physiology, 1992;62:47-50. https:/doi.org/10.1007/BF00376439. 
15. Sewell, D. A., Harris, R. C., Marlin, D. J., \& Dunnett, M. Estimation of the carnosine content of different fibre types in the middle gluteal muscle of the thoroughbred horse. The Journal of Physiology, 1992;455: 447-453.https:/10.1113/jphysiol.1992.sp019310.

16. de Salles Painelli, V., Saunders, B., Sale, C., Harris, R. C., Solis, M. Y., Roschel, H., Gualano, B., Artioli, G. G., \& Lancha, A. H., Jr. Influence of training status on high-intensity intermittent performance in response to $\beta$-alanine supplementation, 2014;46:1207-1215. https:/doi.org/10.1007/s00726-014-1678-2.

17. Kendrick, I.P., Kim, H.J., Harris, R.C., Kim, C.K., Dang, V.H., Lam, T.Q. et al. The effect of 4 weeks b-alanine supplementation and isokinetic training on carnosine concentrations in type I and II human skeletal muscle fibres. European Journal of Applied Physiology, 2009;106;131-138. https:/doi.org/10.1007/s00421-009-0998-5.

18. Howe, S. T., Bellinger, P. M., Driller, M. W., Shing, C. M., \& Fell, J. W. The effect of beta-alanine supplementation on isokinetic force and cycling performance in highly trained cyclists. International Journal of Sport Nutrition and Exercise Metabolism, 2013;23:562-570. https:/doi.org/10.1123/ijsnem.23.6.562.

19. Faria, E. W., Parker, D. L., Faria, I. E. The science of cycling: factors affecting performance - part 2. Sports Medicine, 2005;35:313-337. https:/doi.org/10.2165/00007256-200535040-00003.

20. Bellinger, P. M., Minahan, C. L. Additive benefits of $\beta$-alanine supplementation and sprint-interval training. Medicine and Science in Sports and Exercise, 2016a;48:2417-2425. https:/doi.org/10.1249/MSS.0000000000001050.

21. Higgins, J. P., Altman, D. G., Gøtzsche, P. C., Jüni, P., Moher, D., Oxman, A. D., Savovic, J., Schulz, K. F., Weeks, L., Sterne, J. A., Cochrane Bias Methods Group, \& Cochrane Statistical Methods Group. The Cochrane Collaboration's tool for assessing risk of bias in randomized trials. BMJ (Clinical research ed.), 2011; 343: d5928. https:/doi.org/10.1136/bmj.d5928.

22. Borenstein, M., Hedges, L. V., Higgins, J. P., Rothstein, H. R. Introduction to Meta-Analysis. John Wiley \& Sons, Ltd. ISBN:987-0-470-05724-7; p: 61-117.

23. Bellinger, P. M., Minahan, C. L. Metabolic consequences of $\beta$-alanine supplementation during exhaustive supramaximal cycling and 4000-m time-trial performance. Applied Physiology, Nutrition, and Metabolism, 2016b;41:864-871. https:/doi.org/10.1139/apnm-2016-0095.

24. James, R. M., Cooper, S. B., Robertson, J., Martin, D., Harris, R. C., \& Sale, C. Effect of $\beta$-alanine supplementation on $20 \mathrm{~km}$ cycling time trial performance. Revista Brasileira de Educação Física e Esporte, 2014;28:395-403. https:/doi.org/10.1590/1807-55092014000300395.

25. Glenn, J. M., Smith, K., Moyen, N. E., Binns, A., Gray, M. Effects of acute beta-alanine supplementation on anaerobic performance in trained female cyclists. Journal of Nutritional Science and Vitaminology, 2015a;61:161-166. https:/doi.org/10.3177/jnsv.61.161.

26. De Salles Painelli, V., Saunders, B., Sale, C., Harris, R. C., Solis, M. Y., Roschel, H., \& Lancha, A. H. Influence of training status on high-intensity intermittent performance in response to $\beta$-alanine supplementation. Amino Acids, 2014;46.1207-1215. https:/doi.org/10.1007/s00726-014-1678-2.

27. Glenn, J. M., Gray, M., Stewart, R. et al. Incremental effects of 28 days of beta-alanine supplementation on high-intensity cycling performance and blood lactate in master's female cyclists. Amino Acids, 2015b;47:2593-2600. https:/doi.org/10.1007/s00726-015-2050-x.

28. Glenn, J. M., Gray, M., Stewart, R. W., Jr, Moyen, N. E., Kavouras, S. A., DiBrezzo, R., Turner, R., Baum, J. I., \& Stone, M. S. Effects of 28-Day Beta-Alanine Supplementation on Isokinetic Exercise Performance and Body Composition in Female Masters Athletes. Journal of Strength and Conditioning Research, 2016;30:200- 207. https:/doi.org/10.1519/JSC.0000000000001077.

29. Chung, W., Baguet, A., Bex, T., Bishop, D. J., \& Derave, W. Doubling of muscle carnosine concentration does not improve laboratory 1-hr cycling time-trial performance. International Journal of Sport Nutrition and Exercise Metabolism, 2014;24:315-324. https:/doi.org/10.1123/ijsnem.20130125.

30. Bellinger, P. M., Minahan, C. L. Metabolic consequences of $\beta$-alanine supplementation during exhaustive supramaximal cycling and 4000-m time-trial performance. Applied Physiology, Nutrition, and Metabolism, 2016b;41:864-871. https:/doi.org/10.1139/apnm-2016-0095.

31. Bellinger, P. M., Minahan, C. L. Performance effects of acute $\beta$-alanine induced paresthesia in competitive cyclists. European Journal of Sport Science, 2016c;16:88- 95. https:/doi.org/10.1080/17461391.2015.1005696.

32. Garvican-Lewis, L. A., Clark, B., Martin, D. T., Schumacher, Y. O., McDonald, W., Stephens, \& Menaspà, P. Impact of altitude on power output during cycling stage racing. PloS one, 2015;10: e0143028. https:/doi.org/10.1371/jpurnal.pone.0143028. 